\title{
Canadian Accomplishments in Forest Products Research
}

\author{
by
}

\author{
Clayton Keith ${ }^{1}$
}

Virtually every region in Canada depends to a significant degree on the forest products industry. It is one of the chief elements of Canadian economic activity and the employment of one in every ten Canadians is related directly or indirectly to forest products (Barclay 1978).

While many factors have been vital to the growth of the industry, one important ingredient in the successful development of this industry has been its ability to develop and apply improvements in technology in the processing and marketing of its products. The research and development that has been the foundation for the technological advancement has been conducted by the equipment manufacturing industry and the wood processing industry, and at university, provincial and federal research laboratories. The federal government has always played a major role in wood products R\&D and in the past decade has joined the primary processing industry and a number of provincial governments to support a cooperative national wood products research institute (Forintek).

\section{Historical Background}

Canadian research in forest products essentially began in 1913 when the Forest Products Laboratories of Canada were established under the jurisdiction of the Dominion Forestry Branch in cooperation with McGill University in Montreal. The university provided a site on its campus and some of the necessary buildings. The laboratories were organized in three divisions, timber physics, timber tests and pulp and paper and their overall goals were:

(1) to secure authoritative information on the characteristic mechanical and physical properties of commercial woods and on products obtained from them;

(2) to study and develop the fundamental principles underlying the preservative treatment of wood and the use of wood in the production of fibre products;

(3) to develop ways and means of using wood that under existing conditions was being wasted;

(4) to serve as a public bureau of information on the properties and utilization of forest products; and

(5) to cooperate with consumers of forest products in improving existing methods of use.

\footnotetext{
T'Forintek Canada Corp., 800 Montreal Road, Ottawa, Ontario K1G 325.
}

In 1918, a branch laboratory was established at Vancouver on the University of British Columbia campus to deal with problems pertaining to British Columbia timber that could be coped with most effectively on a local basis. Encouragement for establishing the Vancouver Laboratory is reported to have come from the Department of Aeronautical Supply, Imperial Ministry of Munitions, to test Sitka spruce for use in aircraft construction in the United Kingdom (Minister of Forestry and Rural Development 1968).

By 1925, the Vancouver laboratory had expanded its function beyond engineering and was attempting to meet the particular needs of a rapidly expanding western forest industry. In this year, the laboratory moved to Point Grey, the new site of the University of British Columbia. Under the terms of an agreement with the university, the laboratory staff conducted classes in mechanical engineering and made available the large testing machines for demonstration and research (Minister of Forestry and Rural Development 1968).

In 1927, in the Eastern laboratory, the pulp and paper division was split-off and formed the core of the Pulp and Paper Research Institute, a cooperative laboratory focused on pulp and paper. The remaining divisions moved to Ottawa and were accommodated in quarters at the corner of Pretoria and Metcalfe Streets. The locations of the two forest products laboratories remained unchanged during the ensuing 30-year period while both laboratories grew considerably in staff and expanded in program function.

On the academic scene, faculties of forestry were being considered by a number of Canadian universities. These were eventually established at Toronto (1907), Fredericton (U.N.B., 1908), Quebec (Laval, 1909), Vancouver (U.B.C. 1915), Thunder Bay (Lakehead U. 1971) and Edmonton (U. of Alberta, 1974). In addition, the universities of British Columbia, Toronto, Laval and New Brunswick ultimately developed special programs in wood technology (Mathur 1978).

The research and development demands in support of a rapidly expanding industry led, during the 1950's, to the construction of new facilities for both eastern and western divisions of the Forest Products Laboratories of Canada. The new Ottawa laboratory building opened in 1957 on Montreal Road close to the head office of the federal government's Central Mortgage and Housing Corporation and also to the National Research Council's Division of Building Research. The Vancouver Laboratory occupied its new facilities on N.W. Marine 
Drive in 1958, still on the University of British Columbia campus and adjacent to the UBC Faculty of Forestry.

During the next 20-year period, the two laboratories carried out their research and development functions at these locations without significant interruption. In the late summer of 1978, the federal government, with the support of the industry, privatized the Ottawa and Vancouver Forest Products Laboratories. An interim board of directors was established in December of 1978 and the new organization, Forintek Canada Corp., was incorporated on February 9, 1979 with a mandate to take over the operation of the former two laboratories and perform R\&D for the Canadian wood products industry and for the federal and provincial governments (Chau 1989). Industry support has grown materially during the past 10 years. A new corporate headquarters and laboratory building is currently under construction in Vancouver and is planned to open late in 1990

In addition to the formation of the national wood products institute, support for wood products R\&D has been expanded through the establishment of research programs within the Alberta Research Council (Edmonton) and the Centre de Recherche Industrielle du Québec (Quebec City) and the creation of a Wood Science Technology Centre associated with the University of New Brunswick in Fredericton.

\section{Research Accomplishments}

\section{Resource Properties}

Wood Science. Research relating the properties of wood with its cellular microstructure was pursued in the Montreal laboratory during the 1920's by the American-born Harvard University botany graduate Joseph D. Hale who directed its course of development over a period of 43 years. One of the first tasks and accomplishments in this field was the establishment of a collection of authentic specimens of Canadian woods and the publication of a manual on their microscopic anatomy and identification in 1938. The wood collection was expanded to include specimens from all parts of the world obtained from counterpart laboratories and universities as well as from consultants and specialists returning from overseas assignments. It is now part of a three-institution collection with information available in one computerized catalogue on over 12000 specimens.

Another contribution in this field was Hale's classic work on the variation in specific gravity of wood and its relationship with the rate of growth in the spruces and balsam fir of eastern Canada. This was followed by work on shrinkage anisotropy, the structure and properties of compression wood in eastern conifers, a new technique for determining the fibre saturation point of wood and the development of failure of wood in longitudinal compression.

More recently, emphasis in this program has been on resource evaluation and wood quality. This has involved wood characterization of hybrid poplar clones in eastern Canada and establishing a basis for incorporating wood quality characteristics in tree improvement programs in western Canada. An expertise has been developed and state-of-the art facilities established for tree ring analytical studies by $\mathrm{x}$-ray densitometry. A field wood density tester has been developed.

Information on second growth coastal Douglas-fir forests has recently been made available in a report of a study that examined all aspects of the growth, conversion and utilization of this material. Out of this work, a system of models has been developed to extend the BC Ministry of Forest's biologically-based growth and yield model (TASS), to predict timber value and economic return in addition to yield. Similar work is in progress for lodgepole pine and jack pine.

Wood Chemistry and Biotechnology. In the early years when the federal Eastern laboratory was associated with McGill University, an important part of the program involved research in wood chemistry. Undoubtedly this was owing partly to the importance of the pulp and paper division in the early organization. A significant contribution during this time was the high-calibre training of a number of wood chemistry specialists who have become leaders in this field at universities and at government and industry research laboratories. Prominent names associated with this facility include C.B. Purvis, H. Hibbert, T.E. Timell, H. Schwartz, D. Manchester, N. Levitin and H.H. Brownell to mention just a few.

A wood chemistry group was established in western Canada in 1948 to examine the potential chemical utilization of wood and bark residues. Initial research on western hemlock bark produced three products: tannin material suitable for heavy leathers, an oil-well drilling mud viscosity control agent and a plywood adhesive diluent which contributed substantially to the waterproof glueline. The latter two products, which eventually became industrial silvichemicals after further refinement by an industrial research and development laboratory, are still in use.

Basic data on the chemical composition of Canadian woods was published after several years of diligent investigation. Continued study of some of the resinous extractive components of the commercial eastern pines provided an insight into the problems associated with finish coatings for these species especially when used as exterior siding.

Studies of the chemical nature and reactions of the extractive components in western species led to the development of suitable digester linings to solve the corrosion

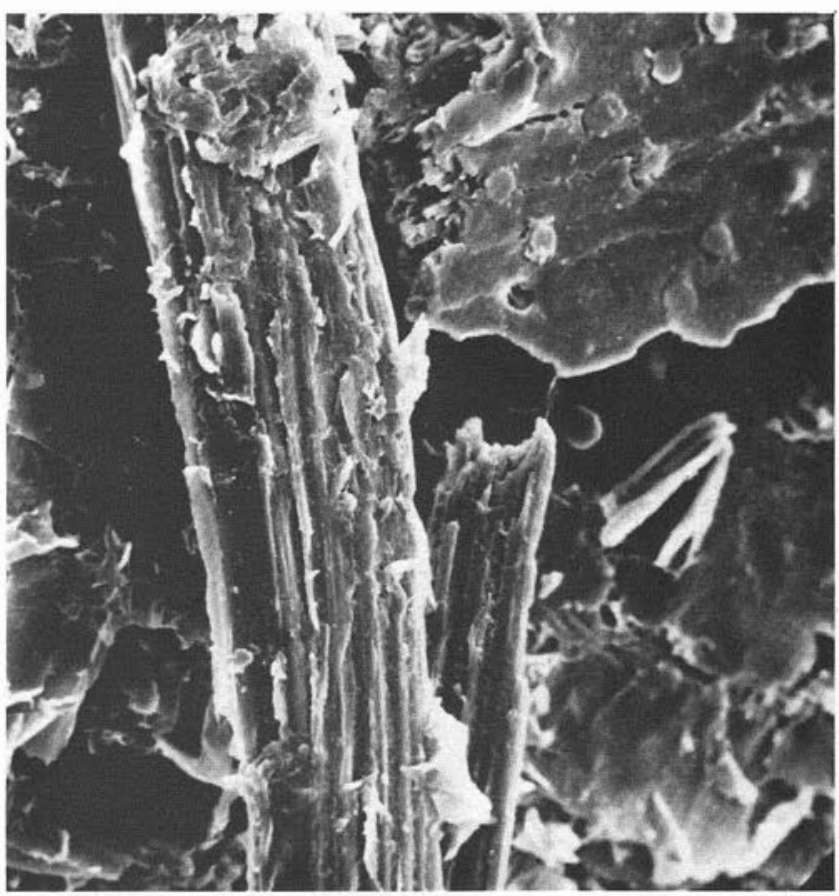

Figure 1. Electron microscopic appearance of aspen wood chips treated with steam in preparation for biological conversion. 
problems with western red cedar. The structure and other chemical data of many of the extractives in these species were published in chemical journals and the information made available to industrial research and development laboratories which carried out further research on their utilization as silvichemicals. Contributions were made to the distribution and identification of extractives that contribute to the color variations and decay resistance of Douglas-fir and other conifers.

Possibilities for utilizing wood wastes, particularly from underutilized species such as aspen poplar as chemical feedstocks for producing organic chemicals, fuels and food were improved by the development of a steam pretreatment process. This process improved the separation of wood into its principal components, cellulose, hemicellulose and lignin and increased the biochemical conversion, by enzyme systems that have been isolated from specific microorganisms, of the cellulose and hemicellulose into specialty products.

\section{Lumber Manufacturing}

Saws and Sawing Equipment. In the mid 1960's, the sawmilling industry faced two major issues. One was the steadily declining diameter of its log supply. The other was the high production costs involved in using headrig technology designed for the larger logs of years gone by. Since then, there have been many important technological changes and developments in this field. Some of these have originated in other parts of the world, notably in the United States and in

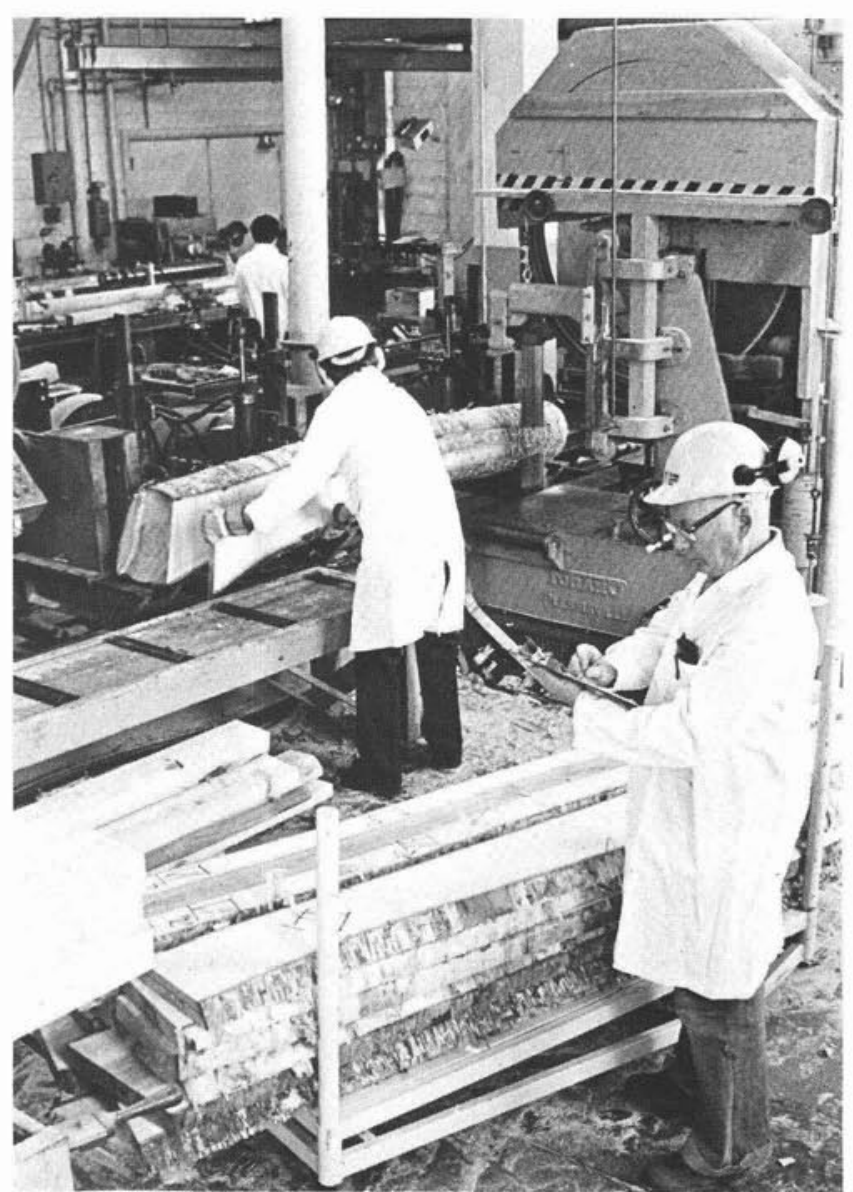

Figure 2. Sawmill improvement studies in progress at an eastern sawmill. the Scandinavian countries. The Canadian responsibility and accomplishment in this area has been to seek out the stateof-the art technology, evaluate it in terms of local applicability and make the information available to the Canadian wood products industry. Early examples of this changing technology were the chipper-canter and the chip-N-saw headrigs. These significantly increased lineal throughput and lumber production per shift. With the continuing decline in log size and quality the industry has pursued new tehcnologies that promise to increase both productivity and lumber recovery. A number of Canadian companies have advanced thin kerf saw technology.

One Canadian company, Cetec Engineering of Burnaby, B.C., in exploring ways to reduce saw variation, has developed a circular "Smart Saw" that regulates its own temperature. Forintek and UBC scientists have developed a thin kerf, highly stressed bandsaw system that has good tracking stability. Forintek has also actively assisted industry by examining splined-arbour circular saws, the "Detenso" laser slot saw and improved methods for stellite tipping of saw teeth. Other recent developments in saw technology include: bandsaw pressure guides, a double guide system for circular saws, an improved method for measuring stress in sawblades, a feed speed and guide arm control for sawing logs with bandsaws and techniques for monitoring sawblade deflection.

Scanning Equipment. In the Canadian lumber manufacturing sector, electronic scanning and optimizing are used in the primary processing area to measure the size and shape of logs. This helps determine how they should be sawn to yield maximum lumber volume. Some of the most futuristic equipment imaginable is making its way into forest products research programs to help industry scan internal and external features of the log. Scientists have examined the entire field of scanning in all areas in which the technology is used, from aerospace to medicine. In addition to monitoring developments around the world, Canadian scientists are conducting original research in the area.

Quality Control. Canadian tree conversion specialists have assembled much of their accumulated knowledge into comprehensive manuals on such topics as "Felling and Bucking" and "Edging and Trimming" for the benefit of hardwood lumber manufacturers. These manuals were prepared specifically to instruct industry woods operators and sawmill staff on the techniques of producing hardwood lumber graded according to the rules of the National Hardwood Lumber Association. The manuals are well illustrated and explain the various principles and rules.

In another area teams of specialists are made available to assist manufacturers of hardwood and softwood lumber in conducting a comprehensive analysis of every phase of their operations and to identify potential improvements and benefits that would result from modifications to practices and processes. Implementation of the results of these studies has improved the efficiency of sawmill operations and the utilization of the forest resource.

A final accomplishment to note in relation to lumber quality control is the Lumber Size Program. This program is a tool designed to identify the minimum rough, green size of lumber required to produce the final dry, dressed market-size product. Its potential benefits include improved lumber recovery resulting from less waste due to oversizing and fewer rejects due to undersizing. With a $4 \%$ increase in lumber recovery, mills producing $100 \mathrm{MM}$ fbm/year stood to 
gain $\$ 600000$ in annual revenue. Participation in the program includes access to the computer program LUSI and to the forms, charts and instructive materials necessary.

Lumber Seasoning. One of the first Canadian contributions in the area of lumber drying was the achievement of improved drying rates in the early natural circulation kilns by removing obstructions from the kiln ventilator stacks. From these humble beginnings, the modern forced-air crosscirculation dry kiln has eventually been developed. The desire to speed-up drying by increasing temperatures and circulation rates has necessitated careful investigations on the influence of these factors on degrade losses. Kiln schedules have been developed for important commercial species and are constantly being revised in relation to new kiln technology.

A number of special drying procedures, such as hightemperature drying, solvent exchange drying and dehumidification drying, have been evaluated and detailed information on their benefits, limitations, etc., has been made available to the industry. Heat recovery systems have been examined for kilns heated with fossil fuels. On the basis of this information, at least one commercial heat-recovery system is now on the market. Considerable research effort has been devoted to the drying of commercial species mixtures such as sprucepine-fir (SPF) and the industry has incorporated the results in improved kiln schedules. Automated kiln controllers are a more recent development and are finding growing acceptance.

Accurate moisture measurement is a critical matter in lumber seasoning. The equipment most frequently used is the direct current electrical resistance moisture meter. These meters require adjustment factors for different temperatures and wood species. Currently tables of correction factors for local conditions are used for this purpose but, with advances in electronics, equipment with these factors built in will soon be available. More recently, new technology for moisture assessment by infra-red sensing developed at Forintek's Vancouver Laboratory is finding wide application.

Seminars and training courses for kiln operators are provided in both eastern and western Canada and are supplemented by prepared manuals and video training aids.

\section{Composite Products}

Veneer and Plywood. Research accomplishments in veneer and plywood production have been substantial. Work on hardwoods has been centred in eastern Canada and has included determining optimum temperatures for peeling individual species and also providing the industry with time schedules for the thawing of frozen logs.

Special tools and techniques have been developed to help the industry establish and maintain accurate lathe lettings for improved veneer quality and instruction manuals have been prepared to assist in training lath operators. Methods for producing ultra-thin hardwood veneers for special purposes have been developed and demonstrated. Techniques for the commercial peeling of poplar logs developed during the 1950's established the basis for the poplar plywood industry. A device to detect areas of unbonded veneers in manufactured plywood panels (sonic blister detector) was developed and after production testing by MacMillan-Bloedel was manufactured and used by industries in both the U.S. and Canada.

More recent developments in veneer and plywood technology include: advances in spindleless lathe technology for

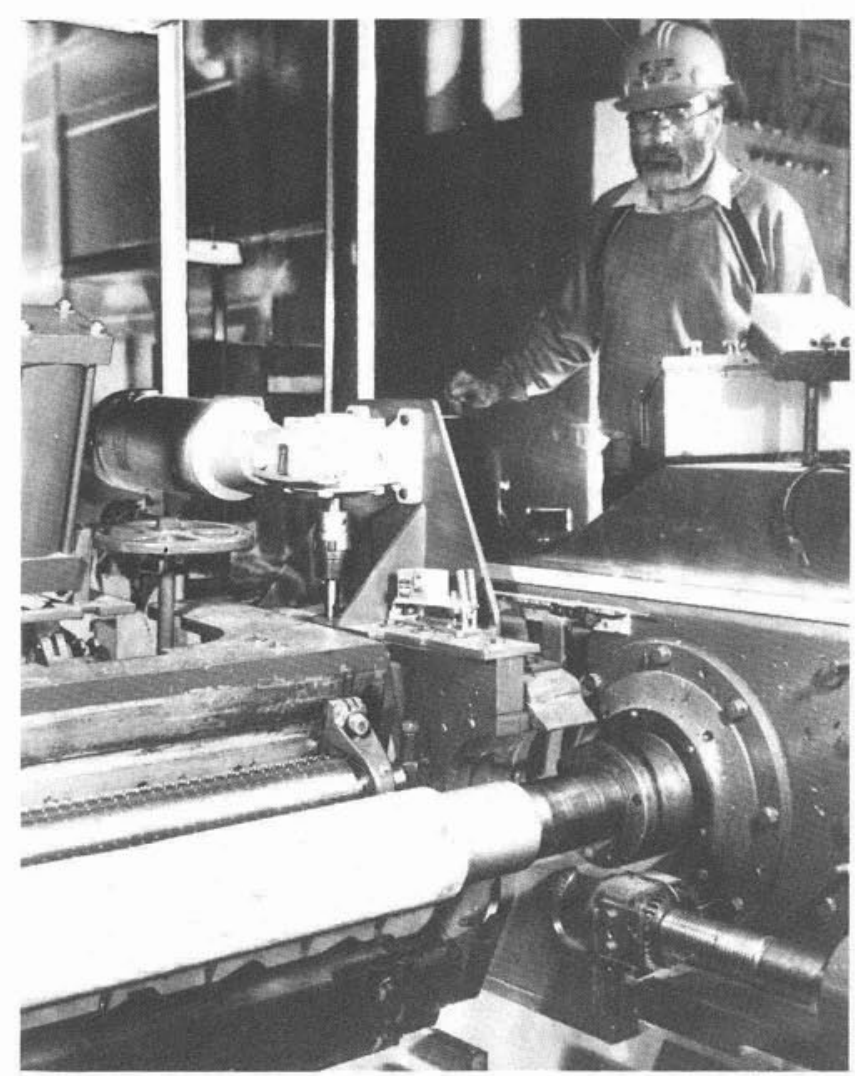

Figure 3. Researcher runs veneer lathe with experimental incising roller.

greater veneer recovery and use of smaller logs, a veneer incisor for improving the rate of veneer drying, a thickness sensor for veneer lathe pitch control, a stepped lathe chuck for veneer production and moisture-tolerant adhesives for plywood panel manufacture.

Waferboard. A Canadian product of the 1970's, waferboard, has revolutionized the panel products industry and established itself as an alternative to plywood for many uses. At the same time, it has created a market for the underutilized Canadian poplar resource. Although it is made with the same "waterproof' resin binder as exterior plywood, waferboard has a tendency to swell excessively in thickness when exposed to dampness. Current research to resolve this problem has been successful and is in the process of commercialization.

The widespread use of waferboard as a building material has resulted in a need to develop better information on its engineering properties. Such properties are currently the subject of a massive research and test program to develop the information required for the CSA 086 Code for Engineering Design in Wood.

Parallam. This is a very new structural wood product developed in Canada by the MacMillan-Bloedel Company after many years of research. The scientists responsible for the invention and development of this product, Derek Barnes and Mark Churchland, received international recognition when they received the Marcus Wallenberg award in 1987. The product consists of oriented fragments of Douglas-fir veneer bonded with waterproof phenolic resin into structural members of large cross-sectional dimension. Parallam furthers the use of wood in non-residential construction and provides opportunities for more complete utilization of a low quality wood. 
Laminated Veneer Lumber (LVL). The feasibility of making lumber-like products from parallel laminations of softwood veneers has been known for at least 25 years. Recently, however, Canadian scientists have adapted the process to utilize veneers of Canadian aspen and mixtures of aspen and birch. The LVL produced from these veneers has strength properties equal to or better than those of solid lumber and has less variability in strength because knots and other defects are randomly distributed among the many plies. The positive results of the laboratory studies and mill trials have prompted one Canadian corporation to announce plans to construct Canada's first LVL plant.

Adhesives. The national forest products laboratories have been the principal source of Canadian information on the long-term durability of exterior grade plywood. This information was developed from outdoor exposure tests that were carried on over many years and provides the basis for codes and standards for the use of various types of adhesives for wood products. As more and more adhesive formulations required evaluation, the Canadian and US laboratories worked in cooperation to develop accelerated aging tests to predict long-term performance.

The rising cost of oil-based phenolic resins has fostered extensive research into alternative adhesives based on renewable resources. In this regard, much attention has been given to lignin, the natural binder of plant cells. Lignin is produced in quantity by the sulphite and kraft pulp and paper industry; it is underutilized and relatively cheap. During the last 10 years, research has progressed to the stage where products incorporating lignin have been demonstrated to be commercially acceptable.

\section{Forest Products Pathology and Preservative Treatment}

Canadian research in timber pathology was initiated in the Montreal laboratories in 1925 by Dr. Clara Fritz who directed this effort in eastern Canada for the next 30 years. Her pioneering studies on red stain in jackpine revealed its cause (the fungus Fomes pini) and showed that its normal development is halted when the timber is sawn and put in service. This permitted the railway companies to use the redstained wood for cross ties and is reported to have resulted in savings $1 "$, to $\$ 2$ million per year. A similar red-heart condition in ludgepole pine was investigated by the western laboratory and it was also shown to be acceptable for use by the railway companies.

Also very early on, pathologists were far-sighted enough to appreciate the importance of building a collection of cultures of wood inhabiting fungi. Now more than 65 years old and containing over 2,500 cultures of fungi, yeasts and bacteria, this collection is one of the most comprehensive in existence. In addition to its traditional use in helping to identify microorganisms isolated from wood, the collection is used for research on the protection of wood against stain or decay using either toxic chemicals or antagonistic strains of microorganisms.

Valuable information has been gathered and made available on the rate of deterioration of insect-killed trees and on the deterioration of sawlogs or pulpwood stored in the bush during summer seasons. Deterioration of wood stored in outdoor chip piles has also been investigated and methods have been found to reduce losses.

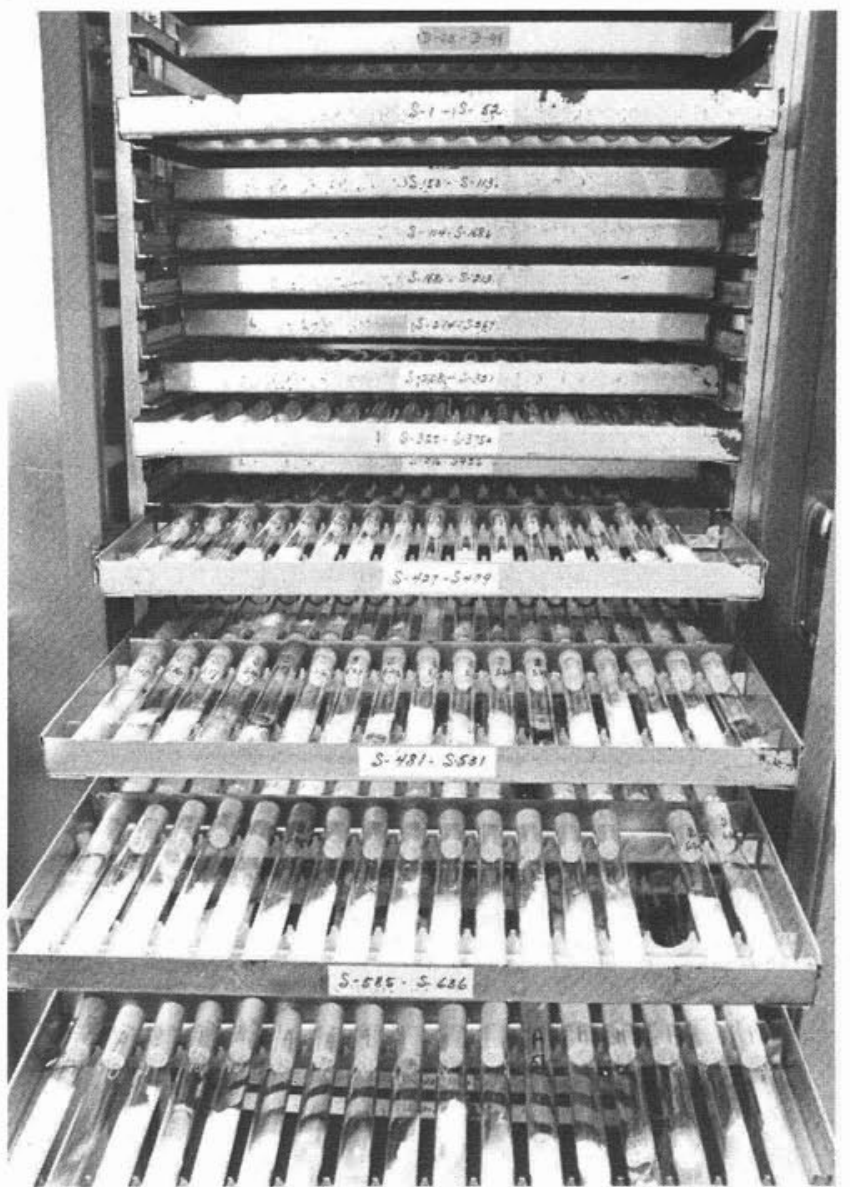

Figure 4. Cultures of microorganisms are used for research in biotechnology and biodeterioration.

Sapstain Protection. The laboratories in both eastern and western Canada have helped their respective industries to maintain their export markets by providing information on methods of protecting their products (particularly packaged green lumber) from stain and decay damage during shipment and storage.

Chlorophenates, the protective chemicals of the past are no longer environmentally acceptable and the search is on to find suitable replacements. Forintek's western laboratory has recently tested several formulations registered in Canada to determine the concentrations required to provide adequate protection and the species that can be protected. Studies to test new electrostatic spray systems for applying anti-sapstain chemicals to wood more effectively are underway and an AntiSapstain Quality Assurance Program for checking retention levels of treatment chemicals is in place.

Scientists at Forintek's eastern laboratory are currently investigating an alternative to chemicals for protecting wood against sapstain, i.e. using other fungi. Use of the Forintek National Culture Collection has made it possible to identify a number of fungi that are antagonistic to the wood staining fungi and either kill them or crowd them out. The effectiveness of such "biocide" fungi and how to employ them are currently being examined.

Preservative Treatment. The search for new preservative formulations and better methods of preservative treatmerit of wood has been a pursuit in both eastern and western 


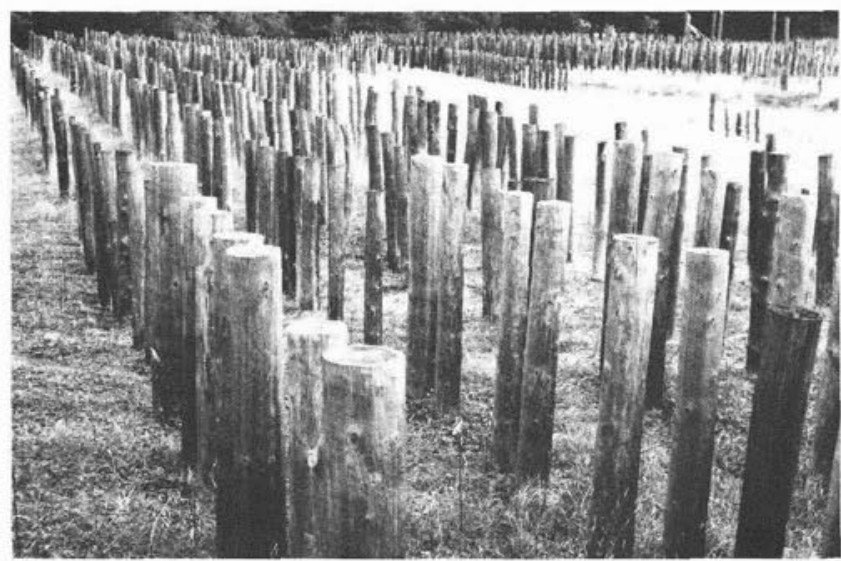

Figure 5. Field testing provides information on effectiveness of wood preservative treatments.

Canada since wood preservation programs were initiated. As a necessary part of such programs, field testing facilities were established in both regions. These sites are used for assessing the in-ground and above-ground performance of such preservative-treated products as poles, fence posts, siding, decking, window joinery, shingles and shakes. Marine testing of certain products and preservatives is conducted at sites in British Columbia and New Brunswick. Recently, Forintek's eastern laboratory has assembled the information gathered over the last 50 years from more than 10000 samples in a computerized data base that is available for consultation on request. These data are important in providing a basis for Canadian codes and standards governing treated wood products.

The field testing of treated wood stakes normally takes between 5 and 10 years. This period is now being reduced considerably by using highly controlled interior facilities (Facility for Accelerated Biodeterioration). These are now being used in cooperative studies with international research organizations to establish the background data necessary for incorporating the results in national and international codes and standards

\section{Wood Building Systems}

Engineering Properties. The initial function and first major accomplishment in this field was to provide reliable data on the mechanical and physical properties of Canadian commercial wood species as a foundation for calculating basic

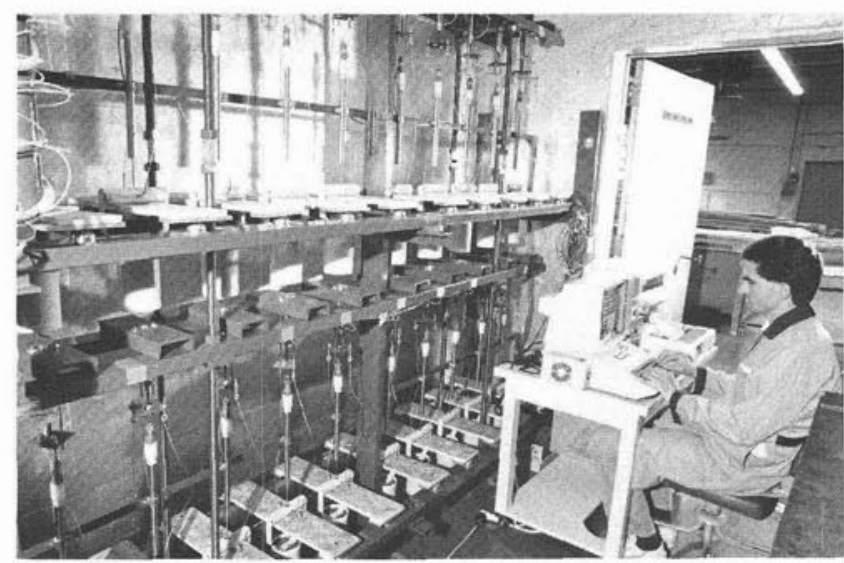

Figure 6. Studies in progress on the long-term strength and stiffness of composite wood products. working stresses. These initial investigations, conducted on small clear specimens were subsequently extended to include an assessment of the short- and long-term strength properties of structural timbers of commercial sizes and grades. These data, together with information collected from an extensive in-grade testing program carried out during the early 1980 's, has formed the basis for the "characteristic design stresses" in the new CSA 086 code. Similar information on a range of structural composite sheathing panel products has been developed over the years and incorporated in this code.

The efficiency of timber connectors has been a challenge in achieving effective and economical design of large timber structures. Important information to improve the design and application of truss plates was a contribution of the 1970's truss-testing program that led to the acceptance of the truss design procedures outlined by the Truss Plate Institute of Canada. More recently, in conjunction with an international cooperative program of research on light frame structures, investigations have provided new information concerning crack propagation induced by nails driven in different species and on the effect of multiple fasteners.

Studies of treated and untreated poles, piles and other round timbers have provided the fundamental engineering design criteria for these products which continue to occupy an important place in the Canadian forest economy. These studies have provided information on the effects of pressure treatment, temperature, incising, and seasoning variables on the strength of these and other timber products for use in exposed or hazardous conditions of service. Investigations of standing fire-killed timber showed that no loss of strength occurred when decay or insect attack was absent and resulted in the appreciable salvage of many fire-ravaged stands.

Detailed studies and exhaustive testing of finger-jointed laminations confirmed their reliability and led to their acceptance by engineering codes. Theoretical and practical examination of stress concentrations around knots, holes, notches, etc., have resulted in better design practices. Extensive testing of glu-lam products and new structural products such as wood I-Beams and MacMillan-Bloedel's Parallam have led to their acceptance and use in a broad range of structural applications.

Fire Performance. Occupant health and safety has always been a concern and the risk of death from fire has been and remains a priority. A broadly based program of research is being conducted by the North American wood products industry to develop the necessary information to support the safe use of wood in building construction. The Canadian contribution has been to develop the basic information on smoke and heat release for different wood species and products. Other research includes the development of models for predating heat transfer and performance of gypsum wall board wood stud assemblies.

Building Construction. The Canadian Forest Product Research laboratories have traditionally played a leading role in the investigation and solution of building construction problems, working in cooperation with such agencies as Canada Mortgage and Housing Corporation and the Institute for Research in Construction of the National Research Council

An intensive research program to develop floor performance criteria was initiated in the early 1970's. The program 
has included laboratory investigations, field testing and consumer studies. Recommendations resulting from this research have been incorporated in the 1990 edition of the National Building Code of Canada.

Preserved wood foundations (PWF's) represent a departure from conventional Canadian building practice and are still under investigation by a number of cooperating agencies. Pentachlorophenol and creosote preservatives as used in the early HUDAC research houses on the Rockcliffe Air Base have now been replaced by waterborne preservative systems, principally chromated copper arsenate. A national survey of 2000 residents of PWF houses was recently conducted to gather information on consumer acceptance of PWF's and to identify a number of units for detailed performance assessment. These studies will provide data to supplement existing information derived from laboratory investigations on dampproofing systems and from field studies that have monitored moisture contents of PWF components over a number of years that confirm the merits of this system.

Extensive research has taken place over the years to develop information to assess and predict the safety and reliability of wood components such as stress skin panels, trusses, truss roof systems and truss floor systems. Some of this pioneering work received international recognition when $\mathrm{Dr}$. R. Foschi, a professor at the University of British Columbia, was awarded the 1982 Marcus Wallenberg Prize for his work on the "Assessment and Prediction of the Structural Reliability of Structures Fabricated from Wood and Wood Products". Dr. Foschi's, and the research of others in this area, makes an important contribution to the continuing use of wood as a major construction material.

\section{Looking to the Future}

If the Canadian forest products industries are to remain competitive and to make even greater contributions to the national economy, it will be necessary to work with greater vigour towards increasing the supply of wood and utilizing our forest growth fully and with maximum efficiency. From the point of view of timber supply, today's forest management decisions will have a profound effect on tomorrow's wood products. Liaison between the forest manager and the wood products manufacturer will be strengthened. More effort will be devoted to linking information on resource properties to processing and marketing strategies thus ensuring we obtain maximum value from our future resource.

The future will see more emphasis on developing new processing technologies that will permit manufacture of higher value products from the resource. In sawmilling, for example, emerging technologies will have a dramatic effect. In the short term, headrigs will become more efficient with the incorporation of new developments in electronic scanning, real time computer control of breakdown operations, thin-kerf sawing and increased automation. In the future, headrigs could incorporate laser and high pressure water jets to slice and split logs with little or no fibre loss to kerf. Computerized scanning for both external and internal defects will increase lumber and value recovery to unprecedented levels.

Research efforts in lumber seasoning will lead to creation of special software for an automated kiln control system using off-the-shelf hardware that will make it easily transferable to industry. Stronger associations will be developed with other industries, particularly the electronics industry. Video tapes will find increased applications for technology transfer and training and will be produced on a variety of subjects such as saw maintenance, lathe operation, sapstain control and sawmill quality control. Expert systems will be incorporated in computer control systems and will play an important role in machine centre maintenance systems and operator training.

With maximum utilization of the existing wood supply in mind, more attention will be directed to developing composite products. Laminated veneer lumbers and a wide variety of new composite products based on wood or combinations of wood and other materials will become common. Biotechnology will play a role in the production of specialty products from residues of other manufacturing processes and will be used to develop detection and control systems as part of more environmentally acceptable systems for the protection and preservation of wood products. Natural products such as lignins will find more widespread use in adhesive systems vital to the development of a variety of composite products.

Material inroads will be made in the non-residential construction market fostered by a technical data base for all wood products that provides the design criteria needed to show architects and designers that wood is at least as efficient and reliable as steel and concrete in any type of building. Computer aided design systems will be used to market and estimate the cost of various buildings. These will be linked to computer aided manufacturing plants that efficiently cut and package these building systems for delivery to the industries' global market.

Meeting the needs of the future will require a strong commitment to science and technology. The scientists and engineers of the wood product industry will find it increasingly important to keep in touch and work collaboratively with their peers in other sectors and industries if timely solutions to global competition are to become a reality.

\section{References}

Barclay, I.A. 1978. A report by the Sector Task Force on the Canadian Forest Products Industry. Ottawa, Ont. June, 1978

Chau, P.K.P. 1989. Forintek Canada Corp. - the First 10 Years. Forintek Canada Corp. Vancouver, B.C. May 1989.

Forintek Canada Corp. 1983-1989. The Forintek Review, Various Issues.

Mathur, V.N.P. 1978. R \& D in solid wood products - a review of non-federal government programs and activities. Environ. Canada, Can. For. Serv. Inf. Report DPC-X-7.

Minister of Forestry \& Rural Development. 1968. Fifty Years of Progress at the Vancouver Forest Products Laboratory 1918-1968. Queen's Printer, Ottawa.

Stephens, R.W. 1988. Forest Products Initiatives for the 1990's. In Management and Utilization of Northern Mixedwoods, Symp. Proc. April 11-14, 1988, Edmonton, J.K. Samoil, editor. Can. For. Serv. Northern Forestry Centre, Infor. Report NOR-X-296.

\section{Colonel John H. Jenkins. Forest Products Research Pioneer}

Undoubtedly the most distinguished name associated with forest products research in Canada is that of Colonel John $\mathrm{H}$. Jenkins. A true pioneer, Col. Jenkins' career in the Forest Products Laboratories of Canada spanned four decades from a 1923 appointment as research scientist in lumber seasoning and wood utilization at the Vancouver Laboratory to Chief Executive Officer of both Vancouver and Ottawa Laboratories and special advisor to the Deputy Minister of Forestry prior to retirement in 1965.

Col. Jenkins also had a distinguished military career, serving with the Canadian Army during both world wars and 


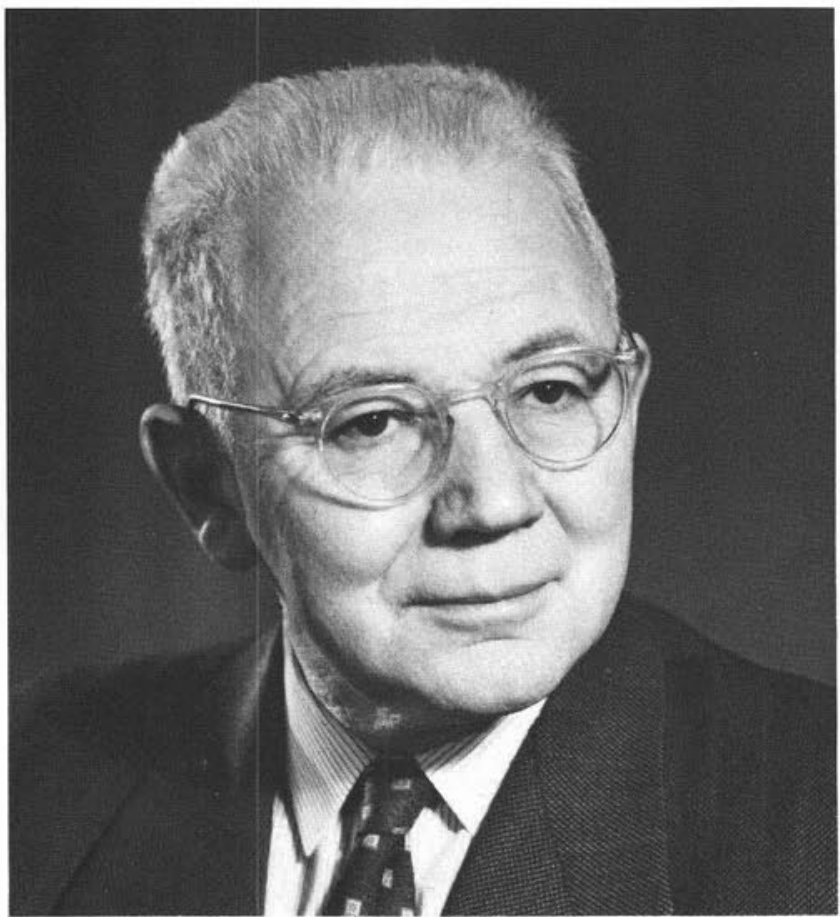

Colonel John H. Jenkins attaining the rank of colonel. For his service as Director of Military Operations and Planning at National Defence Headquarters in Ottawa, he was awarded the Order of the British Empire, the US Legion of Merit, the Belgian Order of Leopold, the Norwegian Cross of Freedom and the Czechoslovakian Order of the White Lion.

Prior to World War II, Col. Jenkins was a productive scientist and author of numerous technical reports and publications dealing with lumber seasoning, lumber manufacture and wood utilization. In addition to his research accomplishment, he pioneered the grade marking of lumber in Canada and his activities in various standards organizations have earned him the title of "Mr. Lumber Standards of Canada". He served as first vice-president of the Canadian Standards Association and as chairman of the Canadian Lumber Standards Administrative Committee. He was honourary director of the Canadian Wood Council, a member of the International Standards Organization's Technical Committee of Lumber, a director of the American Society for Testing and Materials and an officer of the International Union of Forest research Organizations and the Forest Products Research Society.

\section{The Annual Meeting Schedule}

1990 - August 20-24, Fredericton, N.B. Theme: In Pursuit of Excellence in the Forestry Profession

À la recherche de l'excellence professionnelle dans le secteur forestier

1991 - September 22-26, Toronto, Ontario

1992 - Vancouver, B.C.

1993 - Montreal

1994 - Joint with Society of American Foresters
EDWARD

S. FELLOWS

\section{MEMBER}

Canadian Institute of Forestry

Forest Products Research Society etc

\section{FORESTRY \& FOREST PRODUCTS CONSULTANT}

\section{Mail address:}

PO BOX 354

FREDERICTON NB

E3B $4 Z 9$

INDUSTRY DEVELOPMENT - FOREST PRODUCTS -

FOREST ECONOMICS. POLICY AND ADMINISTRATION
Change of Address

Da:e Section

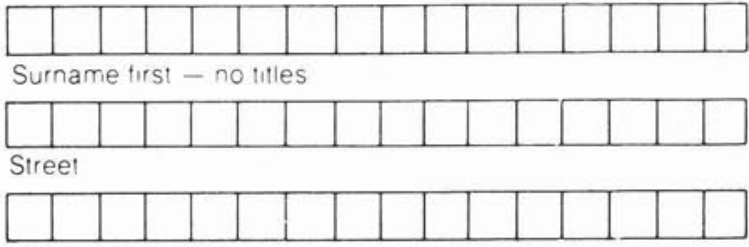

City and Province

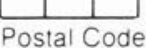

\section{Changement d'adresse}

Da:e Section
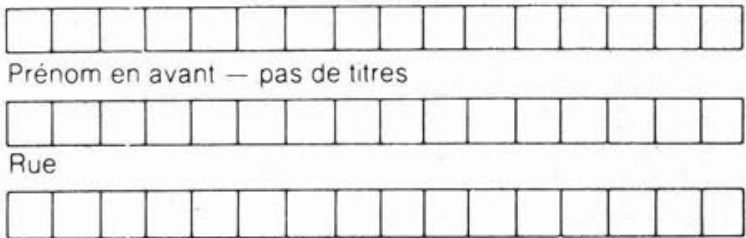

Ville et Province

Code Postale 